\title{
EXPERIÊNCIAS DE MATERNIDADE DE MULHERES COM DOENÇA FALCIFORME
}

\author{
Layla Nayara da Silva Santos ${ }^{1}$ e Evanilda Souza de Santana Carvalho ${ }^{2}$ \\ 1. Bolsista PROBIC/UEFS, Graduanda em Enfermagem, Universidade Estadual de Feira de Santana, e-mail: \\ layalanayarass@gmail.com \\ 2. Orientadora, Departamento de Saúde, Universidade Estadual de Feira de Santana, e-mail: evasscarvalho@yahoo.com.br
}

PALAVRAS-CHAVE: Saúde sexual e reprodutiva, doença crônica, hemoglobina falciforme.

\section{INTRODUÇÃO}

As doenças falciformes constituem um grupo de doenças genéticas que tem como característica comum à presença da hemoglobina S. Essa é uma proteína mutante, cuja principal característica é a de sofrer polimerização sob-baixas tensões de oxigênio (ZANETTE, 2007). Consequentemente as pessoas com doença falciforme podem apresentar uma dificuldade na circulação sanguínea que resultam em isquemia, dor, necrose e disfunções, bem como danos permanentes aos tecidos e órgãos além da hemólise crônica (BRASIL, 2006).

Diante a DF os aspectos sexuais e reprodutivos das mulheres são implicados por complicações da doença e também por temores que circulam nas conversas partilhadas nos cenários de cuidados, dentre eles o temor de uma gravidez difícil, do aborto e de ter um filho com a doença (XAVIER; FERREIRA; CARVALHO; ARAÚJO; CORDEIRO, 2013). De acordo com a literatura, de fato a gravidez é uma situação potencialmente grave para as mulheres com doença falciforme, assim como para o feto e para o recém-nascido; além de apresentar um alto risco de aborto espontâneo. Porém a DF não é contra indicação para a gravidez (BRASIL, 2002), o que requer que os profissionais de saúde e os serviços estejam preparados para acolher as mulheres com DF que decidem engravidar e respeitar seus direitos.

$\mathrm{O}$ enfrentamento do adoecimento traz um impacto não apenas ao corpo biológico, como também uma repercussão no âmbito psicológico, espiritual e socioeconômico das mulheres e suas famílias, influenciando também nas decisões reprodutivas destas. Fazendo-se então necessária conhecer as experiências maternas para o aprimoramento do cuidado com respeito aos direitos sexuais e reprodutivos das mulheres adoecidas. Diante disso, o presente estudo parte da seguinte questão: Como as mulheres com doença falciforme experienciam a maternidade?

Em função disso, pretende-se por meio desse estudo, contribuir para o cuidado destas mulheres através da produção de conhecimentos a cerca de como as experiências maternas são experienciadas pelo adoecido com a DF. Como também, o presente estudo irá fornecer informações não apenas paras os profissionais de Enfermagem, como toda a equipe multiprofissional, visando estimular a adoção de atitudes comprometidas com a finalidade de um cuidado educativo e diferenciado, disseminando o manejo correto com as mulheres com DF, objetivando a redução da morbidade e mortalidade materno-fetais neste grupo específicos.

Deste modo, o objetivo geral deste estudo é compreender as experiências de maternidade de mulheres com doença falciforme. Tendo como objetivos específicos conhecer as motivações de mulheres com doença falciforme para a escolha da maternidade e identificar as limitações para o exercício de suas escolhas de maternidade.

\section{MATERIAL E MÉTODOS OU METODOLOGIA (ou equivalente)}

Para alcançar os objetivos optou-se por um estudo de natureza qualitativa com uma abordagem exploratório-descritiva. O estudo foi desenvolvido na cidade de Feira de Santana, 
envolvendo as Unidades de Saúde e Centros Especializados de Atenção a Pessoas com Doença Falciforme, bem como associações de apoio a pessoas com a doença. Participaram do estudo mulheres diagnosticadas com a doença falciforme, e que já engravidaram. Os critérios de inclusão da pesquisa foram: estar ainda em idade fértil, e idade a partir dos 18 anos.

Para a coleta de dados foi empregada a Entrevista Semiestruturada e o Procedimento Desenho-Estória com Tema (PDE-T). As entrevistas foram gravadas e posteriormente transcritas, as mesmas, realizadas em ambientes restritos, atentando parar a privacidade da pessoa entrevistada. Para o PDE-T, foram oferecidas as mulheres papel em branco, canetas, e aplicou-se estímulos relacionados ao objeto de pesquisa visando motivar as participantes a expressar suas percepções, crenças, vivencias e significados por meio da grafia e em seguida solicitadas a contar estórias tomando por base o que fora desenhado, e por fim foram atribuídos títulos às estórias contadas. Os dados empíricos foram submetidos à análise de conteúdo de Bardin (2011).

Este estudo está vinculado ao projeto "Representações sobre o corpo e a doença falciforme: repercussões sobre a vida cotidiana, o cuidado e a sexualidade". Buscou-se respeitar os aspectos éticos da Resolução ${ }^{\circ}$ 466/12 do Conselho Nacional de Saúde. As participantes convidadas de forma esclarecida e gratuita se voluntariaram, e ao aceitar, para garantir o anonimato em meio à descrição da pesquisa, foi atribuído um código de acordo a ordem das entrevistas. Com base nisso, este estudo portou duas vias do Termo de Consentimento Livre e Esclarecido - TCLE.

\section{RESULTADOS E/OU DISCUSSÃO (ou Análise e discussão dos resultados)}

Foram entrevistadas cinco (05) mulheres, que se mostraram disponíveis para participação, atualmente todas são residentes de Feira de Santana - BA. Todas relataram apresentar complicações decorrentes da DF, como, crises vaso-oclusivas, havendo necessidade ou não de transfusão de concentrado de hemácias, Acidente Vascular Encefálico AVE, lesão bilateral em quadril e úlcera em perna direita, dentre as complicações, a mais citada foi crises vaso-oclusivas, relatada por quatro (04) mulheres; quanto aos companheiros nenhuma tem confirmação de diagnóstico de DF. O número de gestações variou entre uma (01) e quatro (04) gestações; duas mulheres tiveram abortos; todas possuem apenas um (01) filho; com a faixa etária entre dois (02) e dezesseis (17) anos; e três (03) filhos diagnosticados com o Traço Falciforme.

Foram colhidas narrativas diversas, únicas, mas que se apresentam interligadas, e que expressam o quão sensíveis se apresenta essas mulheres para uma gestação, submergiram 5 categorias sendo elas: "Descobrindo-se com a doença", "Implicações para a maternidade", "Atravessando dificuldades", "Encontrando um novo método para enfrentar" e "Vivendo o inesperado".

$\mathrm{Na}$ categoria DESCOBRINDO-SE COM A DOENÇA, surgiram dois temas, "Diagnóstico tardio", e "Reações ao diagnóstico". Em dois casos, ocorreram diagnósticos tardios, o que nos mostra a vulnerabilidade individual dessas mulheres, que seria a convivência com a doença, mas sem o seu conhecimento e pouca compreensão sobre a mesma, e as falas revelam que a descoberta da doença, o desconhecimento sobre a doença pode afetar emocionalmente, gerando insegurança, carência, medo, preocupação com a morte.

Na segunda categoria, IMPLICAÇÕES PARA A MATERNIDADE, emergiram três temas, "Orientação dos profissionais contra a gravidez", "Decisão para maternidade", "Reações e sentimentos experienciados com os planos de maternidade". Atualmente a maternidade traz para as mulheres tentativas, implicações e conflitos distintos. Em algumas entrevistas foram percebidas expressões de indignação pelo fato de que os médicos se colocarem contra a concepção. Foi possível identificar que há ainda coação, ou seja, as 
mulheres com DF elas são desestimuladas, desmotivadas a exercerem seus direitos reprodutivos.

Logo, é necessário então refletir para buscar entendimento de quais as razões e motivos que levam essas mulheres tornarem-se mães, compreendendo a maternidade como multicausal. Sua gravidez pode ser uma busca de autoafirmação, rebeldia, como forma de satisfazer o companheiro por acreditar que esse é o seu desejo, vontade de deixar a casa paterna e acreditam que o filho será a sua passagem para a liberdade ou outros motivos. Não pode ser analisado sem antes estudar todo o contexto social e psíquico no qual essa mulher está inserida e as ideologias herdadas culturalmente. (MOREIRA et al., 2008, apud REZENDE, 2016).

Rezende (2016), afirma que quando gestante, a mulher vivencia sentimentos antagônicos, há momentos de alegria e aceitação, há outros de tristeza e rejeição, ou seja, a gravidez afeta todas as áreas da vida da mulher, inclusive sua condição psíquica. Os sentimentos experienciados por essas mulheres com os planos e maternidade foram os mais diversos. Algumas tiveram que lidar com os conflitos familiares e principalmente com seus parceiros, e o que mais chama atenção é a fala que evidência o medo da morte, o pânico e engravidar.

$\mathrm{Na}$ terceira categoria intitulada, ATRAVESSANDO DIFICULDADES, inclui temas como "Gravidez de alto risco", "Perdas e frustrações", "Limitações impostas pela DF", e "Sentimento enfrentado: MEDO DE MORRER". Quando se identifica a DF e a gravidez, as mulheres foram dirigidas ao pré-natal de alto risco, algumas mesmo sem apresentarem complicações. O acompanhamento pré-natal tem como objetivo identificar e tratar precocemente as complicações hematológicas durante a gravidez. Algumas mulheres relataram por meio da entrevista e até pelo PDE-T, suas limitações físicas, elas se ressentem de não acompanhar o ritmo de seus filhos, ora para cuidar do filho, ora para brincar.

O "medo" apareceu em várias situações, mas podemos entender que o medo é uma resposta emocional aguda, onde demonstra que essas mulheres sentem-se constantemente ameaçadas pela enfermidade.

Na quarta categoria ENCONTRANDO UM NOVO MÉTODO PARA ENFRENTAR, apareceram dois temas, as "Estratégias de enfrentamento", e "Rede de apoio". Após descobrir um diagnóstico considerado grave, nesse período de grandes mudanças na rotina, o apoio da família é essencial. Quanto às estratégias baseadas no problema, as mulheres relataram ter maior aderência e compromisso com o tratamento, e quanto às estratégias focadas na emoção, neste estudo, o suporte religioso foi à estratégia de enfrentamento mais utilizada.

$\mathrm{Na}$ ultima categoria, VIVENDO O INESPERADO, as narrativas apresentaram a "Vivência da gravidez" e os "Significados de ser mãe com DF". O papel da mulher historicamente e culturalmente sempre foi como o de "mãe" e "esposa", mesmo assumindo outros serviços, a maternidade ainda lhe compete, sendo reproduzindo que é sua função procriar.

A maternidade pela compreensão psíquica é vista como uma representação que sofre constantes mutações (REZENDE, 2016). Ela pode apresentar uma rede de sentimentos ambivalentes - triste e alegre -, e regressivos (que podem ser resultante de experiências vividas na infância) - carência, insegurança, levando a mulher a viver intensamente esse momento.

A presença de complicações durante a gestação, juntamente com os medos, origina nas mulheres um conflito e dilema em ser ou não ser mãe novamente. Algumas narrativas confirmam que apesar de todas as evidências científicas comprovarem que para mulheres que são portadoras de doença falciforme a gestação torna-se muitas das vezes inviável devido a complicações que envolvem tanto a saúde materna e fetal, elas conseguiram passar pela 
experiência da gestação, parto e puerpério de forma positiva, gerando nessas mulheres sentimentos de autoconfiança, onde poderão ter a oportunidade de encorajar outras mulheres a vivenciarem também a maternidade.

Em sua totalidade, as narrativas mostraram o quanto essas mulheres se sentem realizadas diante a experiência de maternidade, pios além de passarem por traumas, frustrações e dificuldades, encontraram na maternidade um amor verdadeiro e condicional, uma esperança de vida, uma razão para lutar por sua vida.

\section{CONSIDERAÇÕES FINAIS (ou Conclusão)}

Este estudo buscou conhecer as motivações de mulheres com doença falciforme para a escolha da maternidade, e identificar as limitações para o exercício de suas escolhas de maternidade.

A análise das narrativas permitiu alcançarmos os objetivos do estudo, este nos possibilitou compreender as experiências de maternidade de mulheres com doença falciforme, conhecendo suas motivações e identificando suas limitações.

Depreende-se que o diagnóstico tardio interfere diretamente na qualidade de vida das mulheres com DF, visto que, pode levar ao aumento das complicações, redução da expectativa de vida, levando-as à experiências dolorosas sem explicação, sentimentos negativos, sendo frequentemente o enfrentamento da morte, e o adoecimento psicológico, como depressão.

Os sentimentos relatados pelas as mulheres foram os mais diversos, onde se destacou o medo da morte. O medo da morte é um comportamento cultural e literal, e para vencer este medo, se faz necessário que o significado da vida seja reconstituído. As narrativas evidenciaram que essas mulheres encontraram na maternidade esperança e um motivo para viver e enfrentar a DF.

Sendo que devido às circunstâncias justifica a necessidade de investir na qualificação dos profissionais de saúde para a compreensão e respeito às escolhas que dizem respeito aos direitos sexuais e reprodutivos de mulheres adoecidas crônicas. Visando promover uma reflexão crítica e reflexiva sobre o tema "maternidade no adoecimento crônico" nos ambientes acadêmicos e assistenciais. A fim de contribuir com o fortalecimento das linhas de pesquisa desenvolvidas pelos grupos envolvidos na proposta e elevar a produção científica do Programa de Pós-Graduação e Graduação em Enfermagem da Universidade Estadual de Feira de Santana.

\section{REFERÊNCIAS}

BARDIN, L. 2011. Análise de conteúdo. Lisboa: Edições 70. . 2002. ANVISA. Agência Nacional de Vigilância Sanitária. Manual de Diagnóstico e Tratamento de Doenças Falciformes. - Brasília: ANVISA. . 2012. Conselho Nacional de Saúde. RESOLUÇÃO N $N^{\circ}$ 466, DE 12 DE DEZEMBRO $\overline{D E}$ 2012. Diretrizes e Normas regulamentadoras de pesquisa envolvendo seres humanos. Conselho Nacional de Saúde. DF: Conselho Nacional de Saúde. . 2006. Ministério da Saúde. Secretária de Atenção à Saúde. Departamento de Atenção Especializada. Manual de Condutas Básicas na Doença Falciforme. Brasília.

XAVIER, A.S.G.; FERREIRA, S.L.; CARVALHO, E.S.S.; ARAÚJO, E.M.; CORDEIRO, R.C. 2013. Perception of women suffering from sickle cell anemia regarding pregnancy: an exploratory study. Online braz j nurs [Internet]. Dec [cited year mouth day]; 12 (4), 834-43. ZANETTE, A.M.D. 2007. Gravidez e contracepção na doença falciforme. Rev. Bras. Hematol. Hemoter, 29 (3), 309-312. 